\title{
Size-Dependent Characteristics of Ultra-Fine Oxygen-Enriched Nanoparticles in Austenitic Steels
}

\author{
Yinbin Miao, ${ }^{\mathrm{a}, \mathrm{b}, *}$, Kun $\mathrm{Mo}^{\mathrm{a}}$, Zhangjian Zhou ${ }^{\mathrm{c}}$, Xiang Liu ${ }^{\mathrm{b}}$, Kuan-Che Lan ${ }^{\mathrm{b}}$, \\ Guangming Zhang ${ }^{\mathrm{b}, \mathrm{c}}$, Michael K. Miller ${ }^{\mathrm{d}}$, Kathy A. Powers ${ }^{\mathrm{d}}$, James F. Stubbins, ${ }^{\mathrm{b}, \mathrm{e}}$ \\ a Argonne National Laboratory, Lemont, IL 60439, United States \\ ${ }^{b}$ University of Illinois at Urbana-Champaign, Urbana, IL 61801, United States \\ ${ }^{c}$ University of Science and Technology Beijing, Beijing, 100082, China \\ ${ }^{d}$ Oak Ridge National Laboratory, Oak Ridge, TN, 37830, United States \\ ${ }^{e}$ International Institute for Carbon-Neutral Energy Research (I2CNER), Kyushu University, Fukuoka 819-0395, Japan
}

\begin{abstract}
Here, a coordinated investigation of the elemental composition and morphology of ultra-fine-scale nanoparticles as a function of size within a variety of austenitic oxide dispersion-strengthened (ODS) steel is reported. Atom probe tomography was utilized to evaluate the elemental composition of these nanoparticles. Meanwhile, the crystal structures and orientation relationships were determined by high-resolution transmission electron microscopy. The nanoparticles with sufficient size ( $>4 \mathrm{~nm}$ ) to maintain a $\mathrm{Y}_{2} \mathrm{Ti}_{2-x} \mathrm{O}_{7-2 x}$ stoichiometry were found to have a pyrochlore structure, whereas smaller $\mathrm{Y}_{x} \mathrm{Ti}_{y} \mathrm{O}_{z}$ nanoparticles lacked a well-defined structure. The size-dependent characteristics of the nanoparticles in austenitic ODS steels differ from those in ferritic/martensitic ODS steels.
\end{abstract}

Keywords: oxide dispersion strengthened (ODS) alloy, austenitic steels, atom probe tomography, high-resolution transmission electron microscopy (HRTEM), nanostructure

\section{Introduction}

Advanced structural materials with excellent mechanical performance, outstanding corrosion resistance, and exceptional radiation tolerance at elevated service temperatures are crucial for the development of advanced nuclear fission reactors and future fusion facilities[1]. Mechanical

*Tel: +1 (630)252-7448. Email: ymiao@anl.gov (Y. Miao)

Preprint submitted to Journal of Nuclear Materials

August 7, 2016 
alloying of steel and yttria powders, succeeded by precisely-controlled heat treatments and thermal processing, introduces a dense distribution of ultra-fine oxygen-enriched nanoparticles into a steel matrix $[2,3]$. The existence of such nanoparticles alters the microstructure of conventional steels, and therefore improves the performance in multiple aspects. First, these nanoparticles are capable of enhancing mechanical strength and creep resistance by effectively pinning moving dislocations during plastic deformation and dislocation creep processes[4, 5, 6].Additionally, the abundant interfaces created by the introduction of the nanoparticles into the matrix enhance radiation tolerance by trapping radiation-induced defects $[7,8,9,10]$. These two advantages are favored in solving the material challenges raised by next-generation fission reactors and fusion concepts, qualifying ODS steels as promising candidates for structural materials used in advanced nuclear applications. Previous investigations on ODS steels were concentrated on ferritic/martensitic $(\mathrm{F} / \mathrm{M})$ steels and their advantages in mechanical strength and radiation swelling resistance[11, 12, 13, 14]. However, the superiority of austenitic steels in high-temperature phase stability as well as corrosion and creep resistance can be complemented by the remarkable improvement in mechanical strength and radiation tolerance provided by oxygen-enriched nanoparticles so as to function as ideal nuclear structural materials. In addition, the radiation embrittlement caused by $\alpha^{\prime}$-precipitation[15] in F/M steels would not be a problem for austenitic steels. All these merits enable austentic ODS steels to be prospective materials for use in the nuclear energy industry.

As the excellent properties of ODS steels originate from the presence of ultra-fine oxygen-enriched nanoparticles, the structural and chemical characteristics of these nanoparticles control the performance of the materials. Nanoparticles in F/M ODS steels have been investigated through a series of advanced material characterization techniques. These nanoparticles are composed of $\mathrm{Y}$, Ti, and $\mathrm{O}$, and their composition is particle size dependent. For nanoparticles with radii exceeding $\sim 4$ $\mathrm{nm}$, their phases have been confirmed to be either of the two conventional Y-Ti-O compounds, pyrochlore $\mathrm{Y}_{2} \mathrm{Ti}_{2} \mathrm{O}_{7}$ or orthorhombic $\mathrm{Y}_{2} \mathrm{TiO}_{5}$, based on composition and structure analyses[16]. For those smaller than $\sim 2 \mathrm{~nm}$, the nanoparticles, referred to as nanoclusters (NCs) within this size range, no longer have a well-defined stoichiometry or crystal structure. The most interesting 
phenomenon occurs at the intermediate size regime where the experimental observations are controversial, which will be further discussed in the present study. In austenitic ODS steels, the situation seems to differ. According to the limited available literature[17, 18, 19], the nanoparticles remain crystalline until their radii drop to $2 \mathrm{~nm}$, and preserve a coherent or cubic-on-cubic (CoC) orientation relationship with the austenite matrix. This difference at the atomic level between F/M and austenitic ODS steels influences the microstructural evolution of the nanoparticles and therefore, determines the performance of ODS steels. In the present study, a coordinated experimental effort was undertaken to reveal details of the differences in nanoparticle formation and to better understand the microstructural foundation for the advantages of austenitic ODS steels, towards advancing the development of austenitic ODS steels for advanced nuclear applications.

\section{Experiments}

\subsection{Investigated materials}

Table 1: Nominal compositions of investigated ODS steels (wt $\%$ )

\begin{tabular}{cccccccccccc}
\hline Material & $\mathrm{Fe}$ & $\mathrm{Cr}$ & $\mathrm{Ni}$ & $\mathrm{C}$ & $\mathrm{Si}$ & $\mathrm{Mn}$ & $\mathrm{N}$ & $\mathrm{Mo}$ & $\mathrm{W}$ & $\mathrm{Ti}$ & $\mathrm{Y}_{2} \mathrm{O}_{3}$ \\
\hline ODS 304 & bal. & 18.0 & 8.0 & - & 0.15 & - & - & 1.0 & - & 0.5 & 0.35 \\
ODS 310 & bal. & 24.0 & 18.3 & - & - & - & - & 1.9 & - & 0.3 & 0.35 \\
ODS 316 & bal. & 16.8 & 13.2 & - & 0.7 & 0.4 & 0.2 & 2.5 & - & 0.3 & 0.35 \\
9Cr ODS & bal. & 9.0 & - & 0.06 & 0.18 & - & - & - & 1.5 & 0.5 & 0.35 \\
\hline
\end{tabular}

Three types of austenitic ODS steels were investigated for comparison with the F/M 9Cr ODS steel, as listed in Table 1. The base material powders of those four alloys were mechanically alloyed in an inert atmosphere using a planetary ball mill at $300 \mathrm{rpm}$ with a ball-to-powder ratio of $5: 1$ for 30 hours. For the austenitic steels, the powder tends to attach on the surfaces of pot and bowl. Although using pre-alloyed powder instead of mixed pure metal powders can slightly relieve this attachment phenomenon, this issue was not thoroughly eliminated in this study. Fortunately, the attachment phenomenon seems not to degrade the quality of products. Namely, the only major consequence of the attachment is reducing the powder production. Thus, the relatively low ball-to-powder ratio was adopted so as to maximize the production. As the 
alloying efficiency is also dependent on the impact energy of the ball milling procedure, the low ball-to-powder ratio can be compensated by appropriately adjusting the ball milling speed and endurance. The adopted combination of the ball milling speed and endurance was optimized through a series of tentative tests. The milled powder was then degassed, sealed, and consolidated through hot isostatic pressing (HIP) under a pressure of $100 \mathrm{MPa}$ at $1150^{\circ}$ for 3 hours. Detailed mechanical properties enhanced by the oxygen-enriched dispersoids of the investigated materials have been examined and reported in Refs $[4,14,17,18,20]$.

\subsection{Atom probe tomography}

The atom probe specimens were fabricated from $0.25 \mathrm{~mm} \times 0.25 \mathrm{~mm} \times 10 \mathrm{~mm}$ blanks that were mechanically cut from the bulk materials. The blanks were electropolished into needle-shaped specimens using the standard loop-method and electrolytes in a Simplex Electropointer[21]. In order to ensure circular cross-sections as well as an appropriate radius and taper angle, which is ideal for atom probe investigations, the needle-shaped specimens were annular milled in a Dualbeam FEI Nova 200 Nanolab focused ion beam/scanning electron microscope (FIB/SEM) system[21]. Atom probe tomography (APT) characterizations were performed in an energy-compensated CAMECA local electrode atom probe (LEAP) 4000X HR using laser-mode at a specimen temperature of $30 \mathrm{~K}$, a pulse repetition rate of $200 \mathrm{kHz}$, a focus laser beam energy of either 50 or $100 \mathrm{pJ}$, and a data collection rate between $0.5 \%$ and $4.0 \%$. The laser mode (rather than the voltage mode) was selected because of the poor thermal and electric conductivity of the non-metallic nanoparticles. Data analysis was performed using CAMECA Integrated Visualization and Analysis Software (IVAS).

\subsection{Transmission electron microscopy}

While APT was used to retrieve the detailed space-resolved elemental compositions within the alloy specimens, crystal structure information as well as the spatial distribution of the nanoparticles were examined by transmission electron microscopy (TEM). $3 \mathrm{~mm}$ discs with a thickness of approximately $250 \mu \mathrm{m}$ were cut from the bulk materials using electric discharge machining (EDM). These discs were first mechanically thinned and polished to $100 \mu \mathrm{m}$ thickness and 
$0.05 \mu \mathrm{m}$ roughness by $\mathrm{SiC}$ papers at various grit levels and diamond particle suspensions. The specimens were then electropolished to electron transparency for TEM observation using a solution containing 5 vol.\% perchloric acid and 95 vol. $\%$ methanol at $-14^{\circ} \mathrm{C}$. Both diffraction contrast imaging and high-resolution TEM (HRTEM) investigations were performed on a JEOL 2010 $\mathrm{LaB}_{6}$ TEM operated at $200 \mathrm{kV}$.

\section{Results}

The APT reconstructions of the four investigated alloy samples listed in Table 1 are shown in Figure 1. The sample volumes were derived from the numbers of collected atoms of those investigated samples and a 37\% intrinsic detection efficiency of the LEAP 4000X HR. The domains of the oxygen-enriched nanoparticles were initially located by $6 \%$ oxygen isoconcentration surfaces. Dense distributions of oxygen-enriched nanoparticles were observed in all investigated samples, where the nanoparticles were approximately spherical. The proximity concentrations[22] of $\mathrm{Y}, \mathrm{Ti}$, and $\mathrm{O}$ were calculated based on the $6 \% \mathrm{O}$ isoconcentration surfaces. The summation of these proximity concentrations of a nanoparticle can then be fitted as a Gaussian peak function. The full width at half maximum (FWHM) of the fitted Gaussian function is regarded as the diameter of the oxygen-enriched nanoparticle. Therefore, the nanoparticle radius, $r$, is defined accordingly.

The radii of all oxygen-enriched nanoparticles in the investigated ODS steels were then measured, and the size distributions of these nanoparticles are illustrated in Figure 2. Also given is the size distribution of nanoparticles in ODS 310 that was measured by analyzing the TEM bright field (BF) images, which clearly demonstrates that the radius definition used in this study gives nanoparticle sizes that are comparable to the values from direct observation methods such as TEM.

The statistical information of the nanoparticles was computed based on the APT data, as listed in Table 2. While the average sizes of the nanoparticles are similar among the ODS steels, the number densities and volume fractions vary significantly. This tremendous difference, e.g., up to $44 \mathrm{X}$ difference, can be explained by a non-uniform distribution of the nanoparticles. As 
(a)

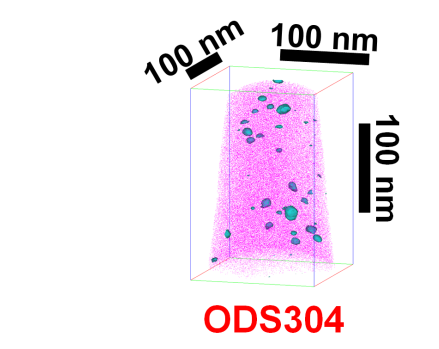

(b)

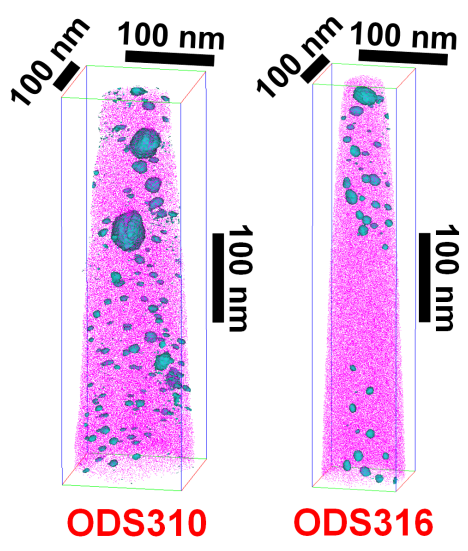

(d)

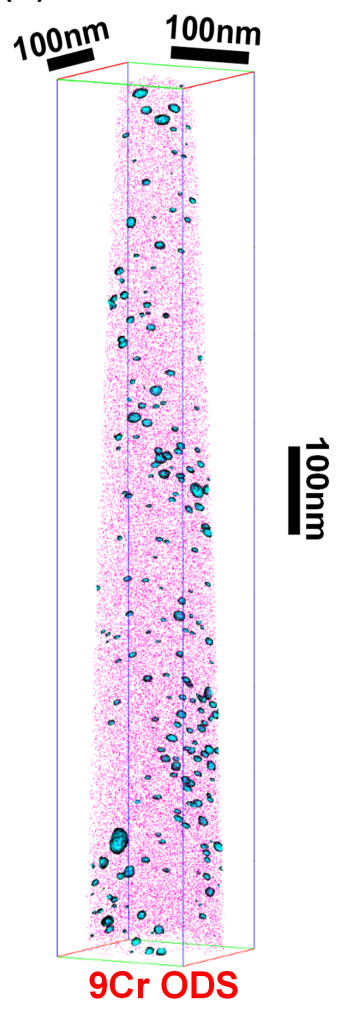

Figure 1: The $6 \% \mathrm{O}$ isoconcentration surface surfaces and $\mathrm{Y} / \mathrm{Ti}$ ratio in the oxygen-enriched nanoparticles: (a), (b), (c), and (d) illustrate the oxygen-enriched nanoparticle domains defined by the $6 \%$ isoconcentration surfaces in ODS 304, ODS 310, ODS 316, and 9Cr ODS, respectively. All four subfigures share the same scale bars 

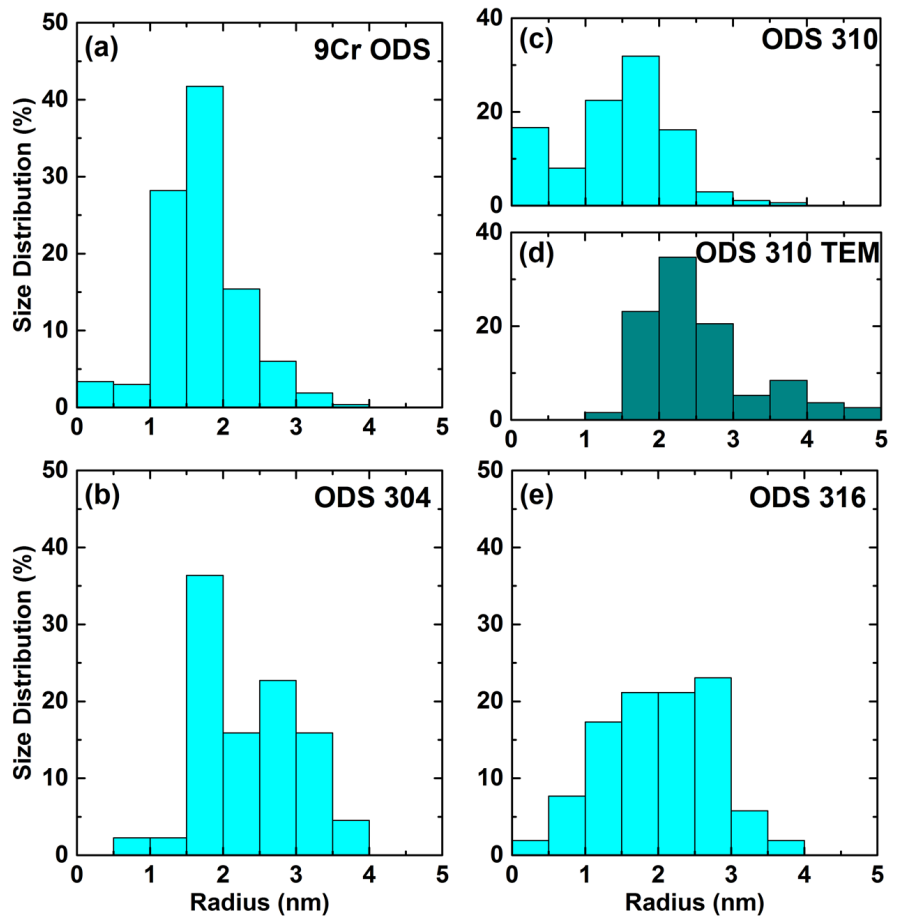

Figure 2: Size distribution of the oxygen-enriched nanoparticles measured by APT; (c) and (d) show a direct comparison of nanoparticles size measured from ODS 310 using APT and TEM, respectively. 
shown in Figure 1, even within the $100 \mathrm{~nm}$ level scale of a single APT specimen, the local spatial distribution of nanoparticles fluctuates.

Table 2: Statistical data of the oxygen-enriched nanoparticles based on the APT investigation.

\begin{tabular}{ccccccc}
\hline Quantity & Symbol & Unit & ODS 304 & ODS 310 & ODS 316 & 9Cr ODS \\
\hline Nanoparticle Number & $N$ & $\mathrm{n} / \mathrm{a}$ & 44 & 636 & 52 & 266 \\
Sample Volume & $V$ & $m^{3}$ & $2.29 \times 10^{-21}$ & $4.16 \times 10^{-21}$ & $2.00 \times 10^{-21}$ & $1.83 \times 10^{-20}$ \\
Number density & $n$ & $m^{-3}$ & $1.9 \times 10^{22}$ & $1.5 \times 10^{23}$ & $2.6 \times 10^{22}$ & $1.5 \times 10^{22}$ \\
Mean radius & $\bar{r}$ & $\mathrm{~nm}$ & $2.4 \pm 0.2$ & $1.5 \pm 0.1$ & $2.0 \pm 0.2$ & $1.7 \pm 0.1$ \\
Volume fraction & $f_{v}$ & $\%$ & 0.14 & 1.76 & 0.12 & 0.04 \\
\hline
\end{tabular}
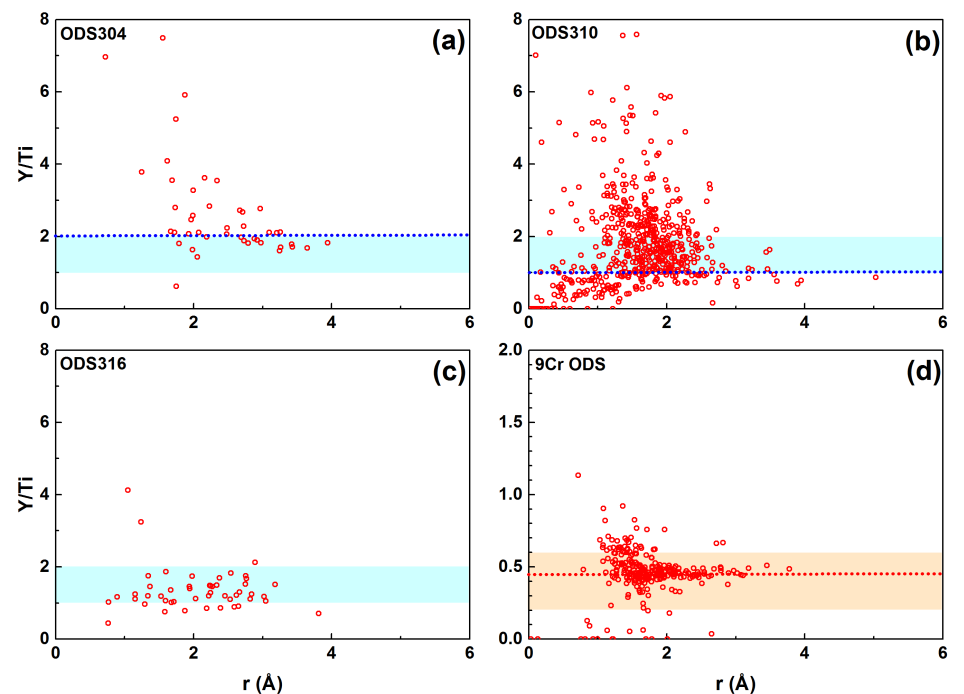

Figure 3: The Y/Ti ratios within the oxygen-enriched nanoparticles defined by the FWHM of the summation of Y-Ti-O concentration in ODS 304, ODS 310, ODS 316 and 9Cr ODS. The blue regimes represent the Y/Ti range from 1 to 2 , which correspond to the stoichiometry of $\mathrm{Y}_{2} \mathrm{Ti}_{2-x} \mathrm{O}_{7-2 x}(0 \leq \mathrm{x} \leq 1)$, whereas the orange regime represents the $\mathrm{Y} / \mathrm{Ti}$ range from 0.2 to 0.6 , which has been reported in the literature[23, 24, 25, 26, 27].

Aside from oxygen, APT mass spectra also indicate the enrichment of $\mathrm{Y}$ and Ti in the nanoparticles. The Y/Ti ratios of the nanoparticles in ODS 304, ODS 310, ODS 316, and 9Cr ODS are illustrated in Figure 3(a), (b), (c), and (d), respectively. The Y/Ti ratio is highly dependent on nanoparticle size. For nanoparticles with a radius less than $\sim 2 \mathrm{~nm}$, their $\mathrm{Y} / \mathrm{Ti}$ 

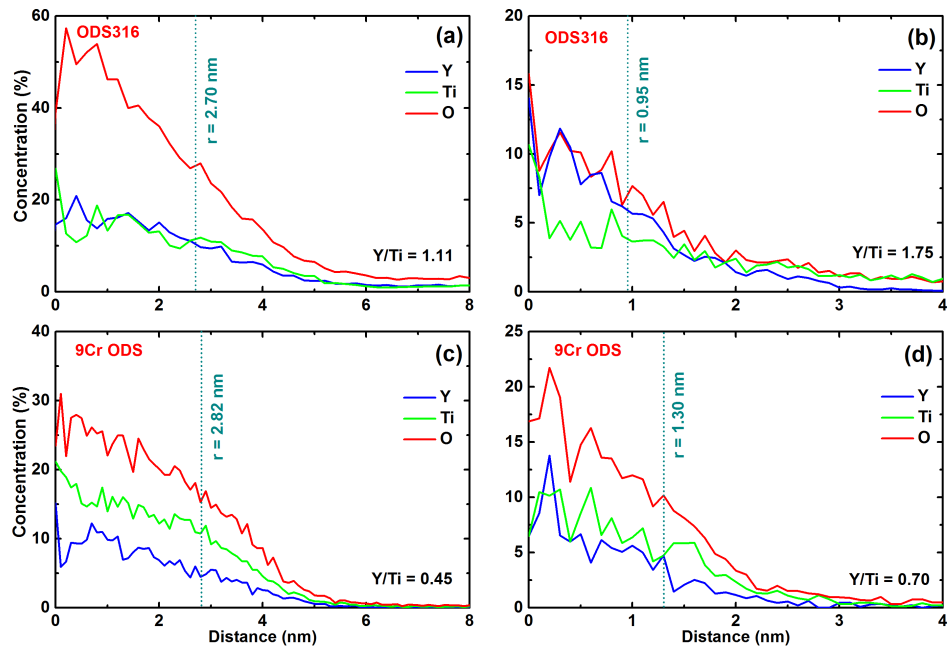

Figure 4: Proximity analysis results of oxygen-enriched nanoparticles of different sizes in ODS 316 compared with those in 9Cr ODS: (a) a large $\left(r_{F W H M}>2 \mathrm{~nm}\right)$ nanoparticle in ODS 316 with well-defined $\mathrm{Y}_{2} \mathrm{Ti}_{2} \mathrm{O}_{7}$ stoichiometry; (b) a small nanoparticle in ODS 316 without well-defined stoichiometry; (c) a large nanoparticle in 9Cr ODS with $\mathrm{Y} / \mathrm{Ti} \sim 0.45$; (d) a small nanoparticle in $9 \mathrm{Cr}$ ODS with Y/Ti of $\sim 0.45$ 
ratios are scattered. As the nanoparticle size increases, the $\mathrm{Y} / \mathrm{Ti}$ ratio converges to a specific value: $\sim 2$ for ODS 304; 1 for ODS 310; 0.45 for 9Cr ODS; and to a narrow range of 1 2 for ODS 316. In austenitic ODS steels, nanoparticles larger than $2 \mathrm{~nm}$ in radius, exhibit a Y/Ti ratio between 1 and 2, which is consistent with the stoichiometry of $\mathrm{Y}_{2} \mathrm{Ti}_{2-x} \mathrm{O}_{7-2 x}(0 \leq \mathrm{x} \leq 1)$. As the mass spectrum is incapable of distinguishing $\mathrm{O}_{2}$ ions from $\mathrm{O}$ ions, APT measurements are likely to underestimate oxygen content. For example, the elemental composition of a large nanoparticle $\left(r_{F W H M}=2.7 \mathrm{~nm}\right)$ should be regarded as $\mathrm{Y}_{2} \mathrm{Ti}_{2} \mathrm{O}_{7}$, as shown in Figure 4(a), although the measured Y:Ti:O is approximately 2:2:6. For nanoparticles smaller than $2 \mathrm{~nm}$, the relative contents of Y, $\mathrm{Ti}$, and $\mathrm{O}$ are random, as shown by Figure 4(b), which, for example, are similar to that of small nanoparticles $(r<2 \mathrm{~nm})$ in $\mathrm{F} / \mathrm{M}$ steels. It is worth mentioning that in 9Cr ODS, although the $\mathrm{Y} / \mathrm{Ti}$ ratio converges to a specific value when the nanoparticles have $r>2 \mathrm{~nm}$, the Y/Ti ratio of $\sim 0.45$ does not fit any conventionally known Y-Ti-O compounds.

The crystal structures and orientation relationships of the oxygen-enriched nanoparticles were investigated by HRTEM. In austenitic ODS steels, those nanoparticles larger than $2 \mathrm{~nm}$ typically have a pyrochlore structure, i.e., the d-spacings match the pyrochlore yttrium titanate phase. A recent study demonstrated that the $\mathrm{Ti}$ in $\mathrm{Y}_{2} \mathrm{Ti}_{2} \mathrm{O}_{7}$ can be replaced by $\mathrm{Y}$ through the vacancy compensation mechanism[28] to form $\mathrm{Y}_{2} \mathrm{Ti}_{2-x} \mathrm{O}_{7-2 x}$ and can maintain the pyrochlore structure up to $x=1$, namely $\mathrm{Y}_{2} \mathrm{TiO}_{5}$ [29]. Despite this, at least two coherent interfacial structures were observed between the pyrochlore structure of the nanoparticles and the austenite matrix in the austenitic ODS steels[19]; the majority of the crystalline nanoparticles have a CoC orientation relationship, as shown in Figure 5. On the other hand, the overwhelming majority of nanoparticles smaller than $2 \mathrm{~nm}$ in austenitic ODS steels exhibited no distinguishable atomic columns (crystallinity) by HRTEM imaging, as illustrated in Figure 6(b), since they lack a well-defined crystal structure. In F/M ODS steel systems, a similar size dependence on the crystal structure was observed, whereby, the crystal structure of ultra-fine $(r<2 \mathrm{~nm})$ nanoparticles, or NCs, could not be determined; namely, they are either fully or partially amorphous, or have an unknown Y-Ti-O structure that has a similar diffraction response as the matrix. However, for the nanoparticles with radii ranging from $\sim 2$ to $\sim 4 \mathrm{~nm}$, the crystal structures in F/M ODS steels are found to 

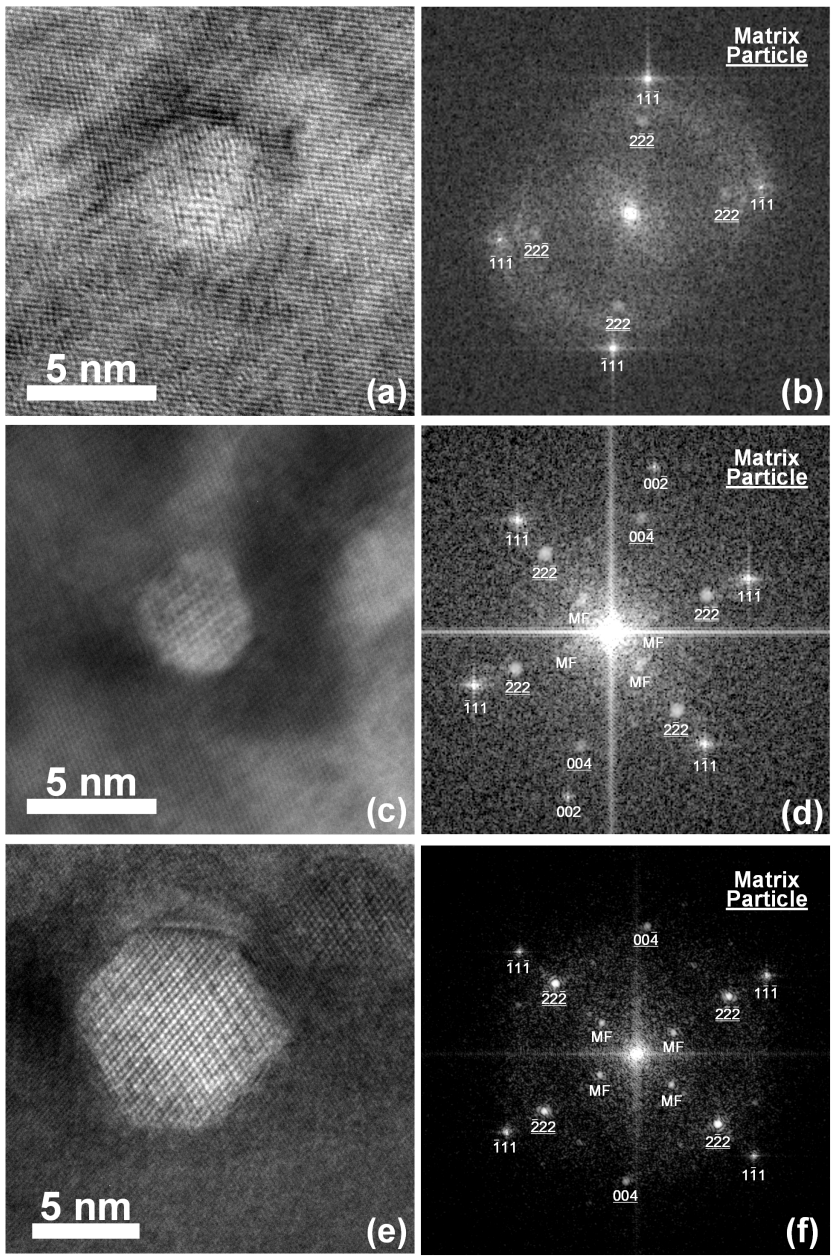

Figure 5: Cubic-on-cubic (CoC) $\mathrm{Y}_{2} \mathrm{Ti}_{2-x} \mathrm{O}_{7-2 x}$ nanoparticles in austenitic ODS steels: (a), (c), and (e) respectively show a nanoparticle in ODS 304, ODS 310, and ODS 316; (b), (d), and (f) respectively illustrate the fast Fourier transformation (FFT) diffraction information corresponding to the HREM images in the left. All the nanoparticles show a CoC orientation relationship with metallic matrix 
be different from those in austenitic ODS steels. Although pyrochlore structured nanoparticles were occasionally observed within this size range[30], this was only for a small fraction of the nanoparticles, whereas the majority fail to exhibit a well-defined crystal structure[31]. Recent synchrotron X-ray scattering results[20] show that Y-Ti-O enriched nanoparticles smaller than approximately $4 \mathrm{~nm}$ in radius do not contribute to the formation of diffraction peaks corresponding to either $\mathrm{Y}_{2} \mathrm{Ti}_{2} \mathrm{O}_{7}$ or $\mathrm{Y}_{2} \mathrm{TiO}_{5}$, further supporting the current observation that nanoparticles smaller than $4 \mathrm{~nm}$ rarely have a well-defined crystalline structure. On the contrary, the majority of the nanoparticles (around 100 observed in HRTEM experiments) in an ODS 316 steel that have radii ranging from $2 \mathrm{~nm}$ to $4 \mathrm{~nm}$ were indexed consistent with a pyrochlore structure, as reported by Miao et al.[19].
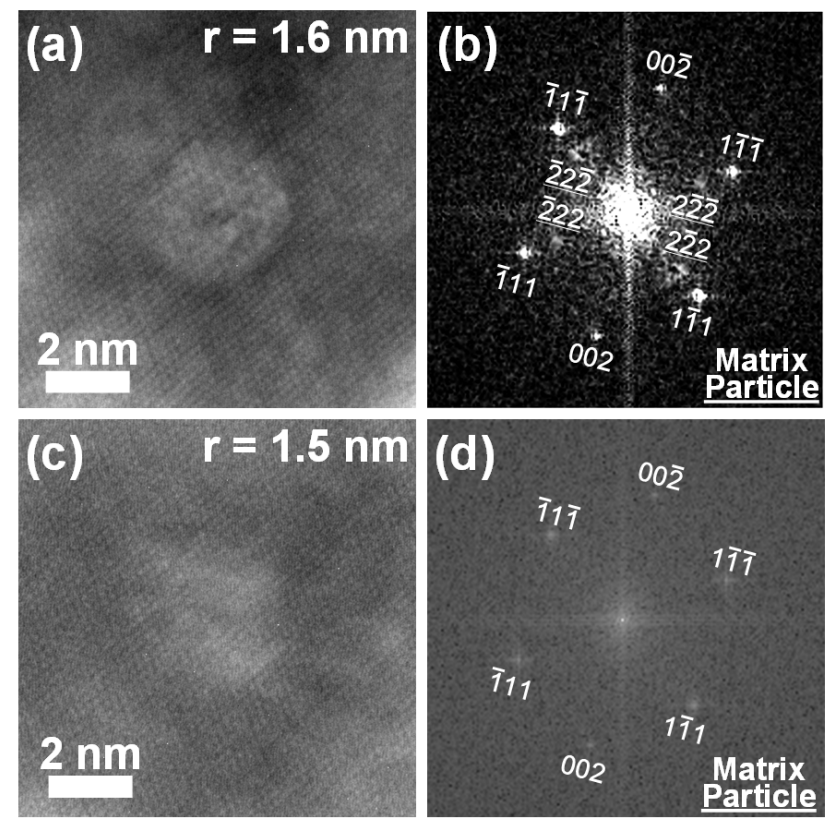

Figure 6: Morphology of nanoparticles smaller than $2 \mathrm{~nm}$ in radius in ODS 310: (a) a crystalline nanoparticle having $\mathrm{CoC}$ orientation relationship with the matrix; (b) the FFT of the nanoparticle shown in (a); (c) a nanoparticle without a well-defined crystalline structure; (d) the FFT of the nanoparticle shown in (c). 


\section{Discussion}

The nanoparticles in austenitic and F/M ODS steels show significant difference as mentioned above in the microstructure investigation results. The origin of this difference in nanoparticle morphology between austenitic and F/M ODS steels can be determined using the APT results. For all three types of austenitic ODS steels investigated in this study, as the nanoparticle radius exceeds $2 \mathrm{~nm}$, the $\mathrm{Y} / \mathrm{Ti}$ ratio converges within a range of approximately 1 to 2 . Within this specific $\mathrm{Y} / \mathrm{Ti}$ regime, the stable crystalline phase $\mathrm{Y}_{2} \mathrm{Ti}_{2-x} \mathrm{O}_{7-2 x}$ with pyrochlore structure or $\mathrm{Y}_{2} \mathrm{TiO}_{5}$ with orthorhombic structure can form. On the other hand, in F/M steels, as the nanoparticle size increases, the $\mathrm{Y} / \mathrm{Ti}$ ratio falls within a range from approximately 0.2 to 0.6 according to numerous reports[23, 24, 25, 26, 27]. This Y/Ti ratio does not match the stoichiometries of any known stable crystalline Y-Ti-O compounds. Therefore, instead of a pyrochlore or orthorhombic structure, a non-conventional Y-Ti-O phase forms. Hypotheses of this non-conventional phase include a NaCl-type TiO-based structure[32], a body-centered cubic (BCC) structure shared with the matrix[33], or simply an amorphous phase. As the nanoparticle radius exceeds $4 \mathrm{~nm}$, $\mathrm{Y}_{2} \mathrm{Ti}_{2-x} \mathrm{O}_{7-2 x}$ nanoparticles with pyrochlore or orthorhombic structures form (probably through a different mechanism), accounting for the corresponding diffraction results reported in previous studies $[14,20]$. In addition, due to the scattered Y/Ti ratios for the nanoparticles with a radii smaller than $4 \mathrm{~nm}$, pyrochlore and orthorhombic structures can also be occasionally observed, as reported by Chen et al.[30] and Cunningham[31]. For the same reason, a limited fraction of nanoparticles that are smaller than $2 \mathrm{~nm}$ in austenitic ODS steels maintain a pyrochlore structure, as illustrated in Figure 6(a) and (b). However, the rest of the nanoparticles that have a Y/Ti ratio outside of the 1 2 range showed no distinguishable lattice structure in HRTEM images (see Figure 6(c) and (d)), implying the absence of a well-defined crystal structure. In Figure 6, both nanoparticles have radii close to $1.5 \mathrm{~nm}$, which is near the lower limit of the HRTEM technique in characterizing oxygen-enriched nanoparticles in steel matrix of typical thickness of an electropolished sample.

The different Y/Ti ratio and nanoparticle morphology observed between F/M and austenitic ODS steels are summarized in Figure 7. This difference may stem from the thermodynamic 


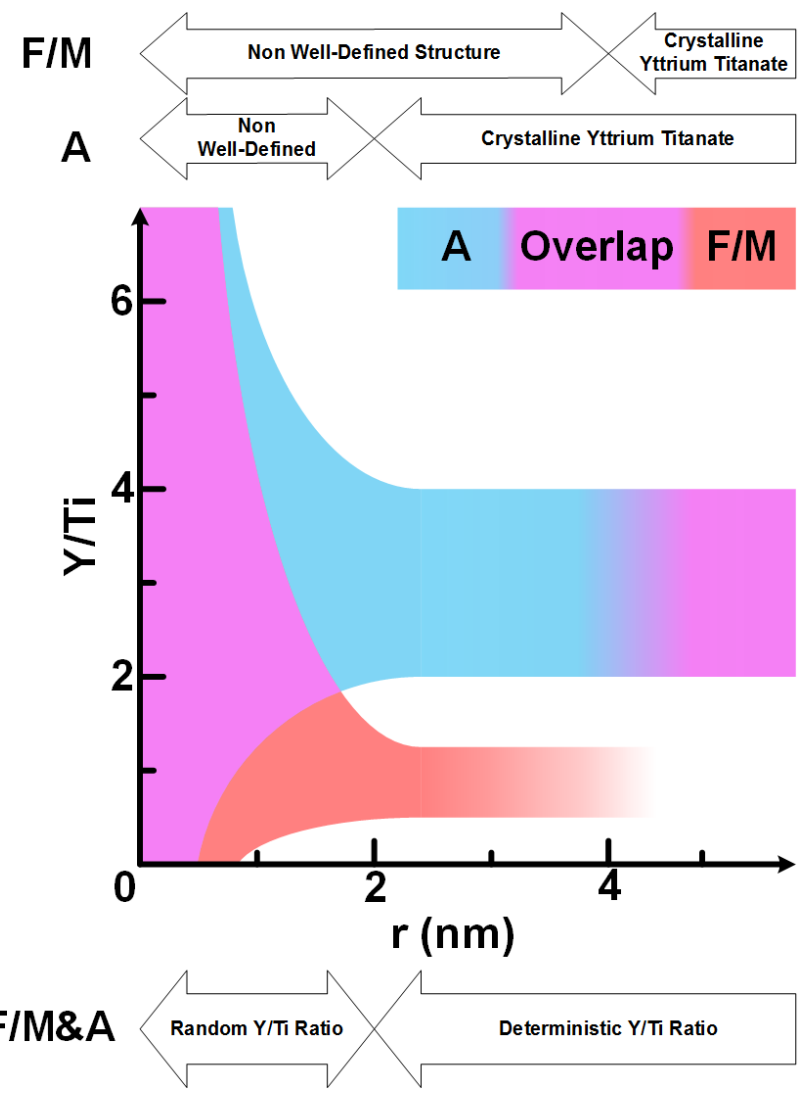

Figure 7: Summary of results from both APT and HRTEM investigations. 
preference at atomistic level of the nanoparticles that determines their nucleation and coarsening during steel fabrication procedures. As described by Zhao et al[34], in F/M ODS steels, the attractive interaction between solute atoms ( $\mathrm{Y}$ and $\mathrm{Ti})$ and oxygen-vacancy $(\mathrm{O}-\mathrm{V})$ pairs results in the nucleation of oxygen-enriched nanoparticles sharing the BCC lattice with the matrix. With a face-centered cubic (FFC) structure stabilized by the complex interactions of $\mathrm{Fe}, \mathrm{Cr}$, and $\mathrm{Ni}$ atoms, the nucleation mechanism of those nanoparticles in austenitic matrices is likely to differ from that in F/M matrices. On the other hand, with the CoC orientation relationship, the misfit, $\delta$, is approximately $6 \%$ between a nanoparticle and austenitic matrix, making the nanoparticle-matrix interface semi-coherent. Therefore, in austenitic ODS steel, the formation of $r<4 \mathrm{~nm}$ nanoparticles not having a well-defined crystal structure may not be preferential thermodynamically compared to a semi-coherent pyrochlore yttrium titanate phase. In addition, the observation of $\mathrm{CoC}$ pyrochlore nanoparticles with radii as low as $1.6 \mathrm{~nm}$ also implies that the nucleation of pyrochlore structured nanoparticles is favored. Meanwhile, as this difference in the fundamental morphology of nanoparticles between austenitic and F/M ODS steels mainly occurs within the radius range from $2 \mathrm{~nm}$ to $4 \mathrm{~nm}$, which plays an important role in the enhancement of mechanical properties and radiation tolerance, and influences the nanoparticle-matrix interfacial strain field and nanoparticle-dislocation interactions, which need to be examined so as to expand the understanding of the respective advantages and prospective applications of both types of ODS steels.

\section{Conclusions}

In summary, the crystal structure of the ultra-fine nanoparticles and their orientation relationship with the steel matrix for a series of austenitic ODS steels were determined by HRTEM, and were compared with nanoclusters observed in F/M ODS steels. The differences were correlated with the size-dependent Y/Ti ratio measured by APT. Significant differences in both morphology and elemental composition of the oxygen-enriched nanoparticles between austenitic and F/M ODS steels were observed, especially for the nanoparticles with radii from $\sim 2 \mathrm{~nm}$ to $\sim 4 \mathrm{~nm}$. The fundamental physics beneath this difference and the corresponding consequences on the 
strengthening and radiation tolerance are worth further computational and experimental investigations.

\section{Acknowledgments}

This work was supported by 973 DOE INL 120293. The TEM experiments were carried out in part at the Frederick Seitz Materials Research Laboratory Central Facilities, University of Illinois, which is partially supported by the U.S. Department of Energy (DOE) under Grants DEFG02-07ER46453 and DE-FG02-07ER46471. Atom probe tomography (APT) was conducted at the Center for Nanophase Materials Sciences, which is a U.S. DOE Office of Science User Facility. M.K.M. was sponsored by the Materials Sciences and Engineering Division, Office of Basic Energy Sciences, U.S. DOE. The author gratefully acknowledge the support of the International Institute for Carbon Neutral Energy Research (WPI-I2CNER), sponsored by the World Premier International Research Center Initiative (WPI), Minister of Education, Culture, Sports, Science and Technology (MEXT), Japan. The efforts involving Argonne National Laboratory were sponsored under Contract no. DE-AC02-06CH11357 between UChicago Argonne, LLC and the U.S. Department of Energy.

\section{References}

[1] S. Zinkle, G. Was, Acta Materialia 61 (2013) 735 - 758.

[2] M. S. El-Genk, J.-M. Tournier, Journal of Nuclear materials 340 (2005) 93-112.

[3] G. Odette, M. Alinger, B. Wirth, Annu. Rev. Mater. Res. 38 (2008) 471-503.

[4] M. Wang, Z. Zhou, H. Sun, H. Hu, S. Li, Mater. Sci. Eng. A 559 (2013) 287-292.

[5] G. Zhang, K. Mo, Y. Miao, X. Liu, J. Almer, Z. Zhou, J. F. Stubbins, Materials Science and Engineering: A 637 (2015) 75-81.

[6] G. Zhang, Z. Zhou, K. Mo, Y. Miao, X. Liu, J. Almer, J. F. Stubbins, Journal of Nuclear Materials 467 (2015) 50-57.

[7] K. Yutani, H. Kishimoto, R. Kasada, A. Kimura, J. Nucl. Mater. 367 (2007) 423-427.

[8] J. Chen, P. Jung, W. Hoffelner, H. Ullmaier, Acta Mater. 56 (2008) 250-258.

[9] Q. Li, C. Parish, K. Powers, M. Miller, J. Nucl. Mater. 445 (2014) 165-174.

[10] P. Edmondson, C. Parish, Q. Li, M. Miller, J. Nucl. Mater. 445 (2014) 84-90.

[11] S. Ukai, S. Mizuta, M. Fujiwara, T. Okuda, T. Kobayashi, Journal of Nuclear Science and Technology 39 (2002) $778-788$. 
[12] R. Klueh, D. Gelles, S. Jitsukawa, A. Kimura, G. Odette, B. Van der Schaaf, M. Victoria, Journal of Nuclear Materials 307 (2002) 455-465.

[13] D. T. Hoelzer, J. Bentley, M. A. Sokolov, M. K. Miller, G. R. Odette, M. Alinger, Journal of Nuclear Materials 367 (2007) 166-172.

[14] K. Mo, Z. Zhou, Y. Miao, D. Yun, H.-M. Tung, G. Zhang, W. Chen, J. Almer, J. F. Stubbins, Journal of Nuclear Materials 455 (2014) 376-381.

[15] W.-Y. Chen, Y. Miao, Y. Wu, C. A. Tomchik, K. Mo, J. Gan, M. A. Okuniewski, S. A. Maloy, J. F. Stubbins, Journal of Nuclear Materials 462 (2015) 242-249.

[16] S. Yamashita, S. Ohtsuka, N. Akasaka, S. Ukai, S. Ohnuki, Philosophical magazine letters 84 (2004) $525-529$.

[17] Y. Miao, K. Mo, Z. Zhou, X. Liu, K.-C. Lan, G. Zhang, M. K. Miller, K. A. Powers, J. Almer, J. F. Stubbins, Materials Science and Engineering: A 625 (2015) 146-152.

[18] Y. Miao, K. Mo, Z. Zhou, X. Liu, K.-C. Lan, G. Zhang, M. K. Miller, K. A. Powers, Z.-G. Mei, J.-S. Park, et al., Materials Science and Engineering: A (2015).

[19] Y. Miao, K. Mo, B. Cui, W.-Y. Chen, M. K. Miller, K. A. Powers, V. McCreary, D. Gross, J. Almer, I. M. Robertson, et al., Materials Characterization 101 (2015) 136-143.

[20] J.-L. Lin, K. Mo, D. Yun, Y. Miao, X. Liu, H. Zhao, D. T. Hoelzer, J.-S. Park, J. Almer, G. Zhang, et al., Journal of Nuclear Materials (2015).

[21] M. K. Miller, Atom probe tomography: analysis at the atomic level, Springer Science \& Business Media, 2012.

[22] O. C. Hellman, J. A. Vandenbroucke, J. Rüsing, D. Isheim, D. N. Seidman, Microscopy and Microanalysis 6 (2000) $437-444$.

[23] M.-L. Lescoat, J. Ribis, Y. Chen, E. Marquis, E. Bordas, P. Trocellier, Y. Serruys, A. Gentils, O. Kaïtasov, Y. De Carlan, et al., Acta Materialia 78 (2014) 328-340.

[24] E. A. Marquis, Applied Physics Letters 93 (2008) 181904.

[25] C. A. Williams, P. Unifantowicz, N. Baluc, G. D. Smith, E. A. Marquis, Acta Materialia 61 (2013) $2219-2235$.

[26] M. Miller, D. Hoelzer, E. Kenik, K. Russell, Intermetallics 13 (2005) 387-392.

[27] M. Miller, K. Russell, D. Hoelzer, Journal of nuclear Materials 351 (2006) 261-268.

[28] Y. Miao, D. Aidhy, W.-Y. Chen, K. Mo, A. Oaks, D. Wolf, J. F. Stubbins, Journal of Nuclear Materials 445 (2014) 209-217.

[29] K. R. Whittle, M. G. Blackford, R. D. Aughterson, G. R. Lumpkin, N. J. Zaluzec, Acta Materialia 59 (2011) $7530-7537$.

[30] T. Chen, E. Aydogan, J. G. Gigax, D. Chen, J. Wang, X. Wang, S. Ukai, F. Garner, L. Shao, Journal of Nuclear Materials 467 (2015) 42-49.

[31] N. Cunningham, Study of the Structure, Composition, and Stability of Y-Ti-O nm-Scale Features in Nano-Structured Ferritic Alloys, Ph.D. thesis, University of California Santa Barbara, 2012.

[32] A. Hirata, T. Fujita, Y. Wen, J. Schneibel, C. T. Liu, M. Chen, Nature materials 10 (2011) 922-926. 
[33] M. C. Brandes, L. Kovarik, M. K. Miller, M. J. Mills, Journal of Materials Science 47 (2012) 3913-3923.

[34] H. Zhao, C. L. Fu, M. Krcmar, M. K. Miller, Physical Review B 84 (2011) 144115. 